\title{
Hypoxia-induced hyperpermeability of rat glomerular endothelial cells involves HIF-2 $\alpha$ mediated changes in the expression of occludin and ZO-1
}

\author{
Peng-Li Luo, Yan-Jun Wang, Yan-Yan Yang and Jia-Jia Yang \\ Department of Nephrology, Affiliated Hospital of Qinghai University, Xining, China
}

\begin{abstract}
This study aimed to investigate the role of hypoxia-inducible factor- $2 \alpha(\mathrm{HIF}-2 \alpha)$ in the expression of tight junction proteins and permeability alterations in rat glomerular endothelial cells (rGENCs) under hypoxia conditions. The expression level of HIF-2 $\alpha$ and tight junction proteins (occludin and ZO-1) in rGENCs were examined following $5 \%$ oxygen density exposure at different treatment times. HIF-2 $\alpha$ lentivirus transfection was used to knockdown HIF- $2 \alpha$ expression. Cells were divided into four groups: 1) control group (rGENCs were cultured under normal oxygen conditions), 2) hypoxia group (rGENCs were cultured under hypoxic conditions), 3) negative control group (rGENCs were infected with HIF-2 $\alpha$ lentivirus negative control vectors and cultured under hypoxic conditions), and 4) Len group (rGENCs were transfected with HIF-2 $\alpha$ lentivirus and cultured under hypoxic conditions). The hypoxia, negative control, and Len groups were kept in a hypoxic chamber $\left(5 \% \mathrm{O}_{2}, 5 \% \mathrm{CO}_{2}\right.$, and $90 \%$ $\mathrm{N}_{2}$ ) for $24 \mathrm{~h}$ and the total content of occludin and ZO-1, and the permeability of rGENCs were assessed. With increasing hypoxia time, the expression of HIF-2 $\alpha$ gradually increased, while the expression of occludin decreased, with a significant difference between groups. ZO-1 expression gradually decreased under hypoxia conditions, but the difference between the 24 and $48 \mathrm{~h}$ groups was not significant. The permeability of cells increased following 24-h exposure to hypoxia compared to the control group $(\mathrm{P}<0.01)$. The knockdown of HIF-2 $\alpha$ expression significantly increased occludin and ZO-1 content compared with hypoxia and negative control groups $(P<0.01)$, while permeability was reduced $(P<0.01)$. Hypoxia increased $H I F-2 \alpha$ content, inducing permeability of rGENCs through the reduced expression of occludin and ZO-1.
\end{abstract}

Key words: Hypoxia; HIF-2 $\alpha$; Rat glomerular endothelial cells; Tight junction; Permeability

\section{Introduction}

The kidney is sensitive to changes in oxygen delivery. Hence, this makes the kidney prone to hypoxia injury. Proteinuria studies have demonstrated the existence of a correlation with high altitude and hypoxia. For example, acute hypoxia causes a 2 to 3 -fold increase in urinary protein excretion (1). Chronic hypoxia also increases the excretion of proteinuria. Five percent of Tibetans were found to have microalbuminuria (2) and 6/27 (22\%) of chronic mountain sickness patients had proteinuria $>1 \mathrm{~g} / 24 \mathrm{~h}$, which occurs to natives and long-time residents of altitudes above $2500 \mathrm{~m}$ because of hypoxia (3). The mechanism of hypoxia-induced proteinuria remains unclear. From a pathophysiologic point of view, the presence of protein in the urine reflects a size-selective dysfunction of the glomerular barrier and is often associated with hemodynamic, hypertension, diabetes, or glomerulopathy.

The glomerular barrier comprises the single glomerular capillary lined by the glomerular endothelial cells, the glomerular basement membrane, and the specialized epithelial cells, that is, podocytes that cover the basement membrane on the side facing the urinary space. The barrier allows for high filtration rates of water, non-restricted passage of small and middle-sized molecules, and almost total restriction of serum albumin and larger proteins. Perturbation of the components of the barrier can result in the clinical endpoints of proteinuria.

However, the molecular mechanisms that lead to proteinuria are poorly understood. One possibility is that it is due to abnormal endothelial function. There is now considerable evidence to suggest that contraction of endothelial cells may change intercellular cleft size by endothelial tight junction modulation (4), and that transcellular holes influence fluid and macromolecular movement across the vascular wall (5).

The tight junction (TJ) between cells is important for maintaining capillary permeability. The intercellular gap is

Correspondence: Peng-Li Luo: <luopengli_cn@163.com> 
increased when the TJ is damaged by various causes, which may lead to the increase in vascular permeability (6). The disruption of the TJ between glomerular endothelial cells (GENCs) may induce capillary hyperpermeability, proteinuria, inflammatory cell infiltration, and progression of kidney disease $(7,8)$. However, little is known about the modulation of $\mathrm{TJ}$ and the mechanisms underlying these changes in a hypoxia environment.

Hypoxia-inducible factor (HIF), a basic helix-loop-helix transcription factor composed of an oxygen-sensitive $\alpha$ subunit and a constitutively expressed $\beta$ subunit, is an important regulatory factor that allows individual cells to adapt to hypoxia (9). Under normoxic conditions, the HIF- $\alpha$ is hydroxylated by specific prolyl hydroxylase (PHD) and is rapidly degraded via the ubiquitin-proteasomal system. In hypoxia, PHD-mediated hydroxylation is inhibited, and HIF- $\alpha$ escapes degradation and dimerizes with HIF- $\beta$ to drive the transcription of target genes that control a variety of adaptive responses to hypoxia $(10,11)$. HIF-1 $\alpha$ is expressed weakly in the outer cortex and strongly in some tubular and collecting duct epithelial cells. HIF- $2 \alpha$ was localized to glomeruli with dense staining in the nuclei of podocytes and microvascular endothelial cells (9). In one report, mice with HIF- $2 \alpha$ deficiency in endothelial cells presented increased vessel permeability, although without involvement of tight junction proteins (12). This indicates that HIF-2 $\alpha$ may interfere in normal permeability of blood vessels, although the precise mechanisms in each different condition remain unclear.

To further investigate the mechanisms of cell hyperpermeability induced by hypoxia, we analyzed the effects of hypoxia on TJ proteins in rat glomerular endothelial cells (rGENCs), as well as the role of HIF-2 $\alpha$ in the underlying mechanism of barrier regulation.

\section{Material and Methods}

\section{Chemicals and antibodies}

Antibodies to HIF- $2 \alpha$, occludin, and zonula occludens (ZO-1) were purchased from Invitrogen Life Technologies (USA) and GAPDH was purchased from Proteintech Group Inc. (USA). Millicell-ERS was purchased from Millipore (USA). Lipofectamine 2000, 293T cells and Opti-MEM I reduced Serum Media were purchased from Invitrogen.

\section{Cell culture}

rGENCs were purchased from ATCC (USA). rGENCs cultures were established and characterized, as previously described (13). Briefly, rGENCs were grown in RPMI-1640 medium (Gibco-BRL, USA) supplemented with $10 \%$ fetal bovine serum (Gibco-BRL) and 10\% NuSerum (SigmaAldrich, USA) in a cell incubator at $37^{\circ} \mathrm{C}$ under $5 \% \mathrm{CO}_{2}$. When cells reached $70-80 \%$ confluence, the cultures were transferred into an automatically controlled Multi Gas Incubator (YCPHOSPHO- 50S, BaiDianTech, China), in which the oxygen levels $\left(5 \% \mathrm{O}_{2}, 5 \% \mathrm{CO}_{2}\right.$, and $\left.90 \% \mathrm{~N}_{2}\right)$ and temperature $\left(37^{\circ} \mathrm{C}\right)$ were maintained for various incubation durations $(6,12,24$, and $48 \mathrm{~h})$. The control group was exposed to a normal environment $\left(20.9 \% \mathrm{O}_{2}\right)$. Then, HIF- $2 \alpha$ lentivirus transfection was used to knock down HIF- $2 \alpha$ expression in rGENCs. These cells were divided into four groups: 1) control group (rGENCs were cultured under normal oxygen conditions); 2) hypoxia group (rGENCs were cultured under hypoxic conditions); 3) negative control group (rGENCs were infected with HIF-2 $\alpha$ lentivirus negative control vectors and cultured under hypoxic conditions); and 4) Len group (rGENCs were transfected with HIF-2 $\alpha$ lentivirus and cultured under hypoxic conditions). The hypoxia, negative control, and Len control groups were kept in a hypoxic chamber $\left(5 \% \mathrm{O}_{2}, 5 \% \mathrm{CO}_{2}\right.$, and $90 \% \mathrm{~N}_{2}$ ) for $24 \mathrm{~h}$, then the total content of occludin and ZO-1 and the permeability of rGENCs were assessed.

\section{Lentiviral vector construction and transfection}

The lentivirus vector system and plasmids (pLP1/pLP2/ VSVG) used to silence HIF- $\alpha \alpha$ expression in rGENCs were purchased from Shanghai BIOSH Company (China). One shRNA sequence target of mRNAHIF-2 $\alpha$ (Rattus norvegicus, NM-023090.1) from 1237 to 1257 bp gene was synthesized, annealed, and ligated into the pGMLVSC5 vector with BamH I/EcoR I sites. A scrambled shRNA was used as a negative control. The recombinant lentivirus was packaged by transfecting the shRNA plasmids and lentiviral packaging vectors into 293T cells, according to manufacturer's instructions of Lipofectamine 2000 (Invitrogen). At $48 \mathrm{~h}$ after transfection, lentivirus particles were harvested from the culture medium. rGENCs were seeded into 6-well plates and cultured for $24 \mathrm{~h}$, the supernatant was discarded and $200 \mu \mathrm{L} /$ well of virus suspension was added to medium containing polybrene (concentration is $5 \mu \mathrm{g} / \mathrm{mL}$ ). Following $12 \mathrm{~h}$ of cell culture, puromycin $(0.5 \mu \mathrm{g} / \mathrm{mL})$ was added to the medium and stable clones were maintained in $1 \mu \mathrm{g} / \mathrm{mL}$ puromycin until distinct colonies appeared large enough for colony picking. The colony cells were selected and cultured in culture bottle with DMEM containing 10\% FBS for subsequent experiments. Knockdown efficiency was determined by western blot analysis after infection.

\section{Western blot analysis}

Endothelial cells were treated with lysis buffer and centrifuged at $15.000 \mathrm{~g}$ for $10 \mathrm{~min}$ at $4^{\circ} \mathrm{C}$. The supernatant was collected for western blotting or stored at $-80^{\circ} \mathrm{C}$. Equal quantities of protein were loaded onto a gel for $15 \%$ SDS-PAGE (Sigma-Aldrich). Separated proteins were transferred onto polyvinylidene difluoride membranes (Millipore, France) and incubated with rabbit anti-rat ZO-1 and occludin antibody (1:2.000; Santa Cruz Biotechnology, Inc. USA) overnight at $4^{\circ} \mathrm{C}$. After washing with phosphatebuffered saline (PBS), an appropriate horseradish peroxidaseconjugated goat anti-rabbit polyclonal secondary antibody (1:3.000; Beyotime Inc., China) was added and cultured for one hour at room temperature. Band intensities were 


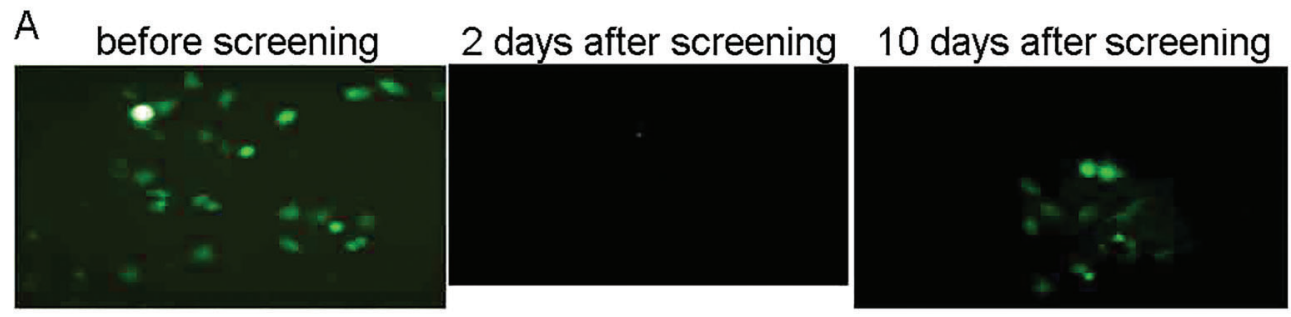

B

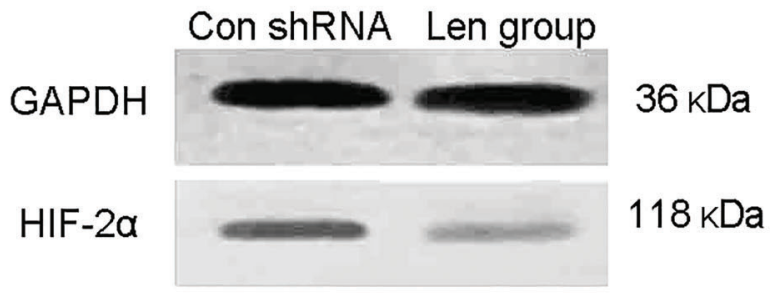

Figure 1. Efficiency assessment of lentiviral vector transfecting in rat glomerular endothelial cells (rGENCs). $A$, Screening of monoclonal cells by puromycin amino nucleoside. The distinct colonies were formed at 10 days after screening by puromycin (fluorescence microscopy $\times 200$ ). B, Expression of HIF-2 $\alpha$ was detected by western blot to evaluate the efficiency of lentiviral vector transfecting in rGENCs. Con shRNA: negative control group; Len group: HIF-2 $\alpha$ lentivirus transfected group; GAPDH: glyceraldehyde-3phosphate dehydrogenase.

quantified by Quantity One 2.0 software (Bio-Rad, USA). The experiment was repeated 3 times.

\section{Transendothelial electrical resistance (TEER)}

The electrical resistance across the confluent cell monolayer was measured using the Millicell-ERS system (Millipore), according to manufacturer's instructions. Briefly, cells were grown to post-confluence on transwell filters (Corning Costar Inc., USA) and treated according to protocol. The shorter electrode was placed within the Millicell culture plate insert and the longer electrode was placed in the outer well. The resistance of the culture or cell-free plate (blank) was measured from three different equidistant points across the inner and outer wells until a stable value was measured each time. The resistance of the blank was subtracted from that measured with endothelial cells (net resistance). The TEER unit area $\left(\mathrm{K} \Omega \cdot \mathrm{cm}^{2}\right)$ was calculated by multiplying the net resistance by the area of the culture plate insert.

\section{Statistical analysis}

All experiments were repeated at least three times. Data are reported as means $\pm S D$. Statistical analysis was carried out using SPSS 16.0 software (SPSS Inc., USA). One-way ANOVA was used to detect the differences among groups. $\mathrm{P}<0.05$ was considered statistically significant.

\section{Results}

\section{Efficiency assessment of lentiviral vector transfection in rGENCs}

Puromycin was used on the selected monoclonal cell population after lentiviral particle transfection. Cell proliferation and survival could be observed through the display of enhanced green fluorescent particles using a fluorescent microscope. The distinct colonies were formed at 10 days after screening by puromycin. The expression of HIF- $2 \alpha$ was detected by western blot, and results confirmed that the expression level of HIF-2 $\alpha$ was restrained (Figure 1). This indicated that the transfection condition was set stably. Cells were successfully transfected and were stored for follow-up experiments.

\section{Influence of hypoxia on the expression of HIF-2 $\alpha$, occludin, and ZO-1}

In order to examine the effect of treatment duration, cells were exposed to hypoxia for 12,24 , and 48 hours. Results revealed that the expression of HIF- $2 \alpha$ was significantly higher $(P<0.01)$, and the expression of occludin and ZO-1 significantly lower $(\mathrm{P}<0.01)$ compared to the control group. With the elongation of hypoxia time, the expression of HIF-2 $\alpha$ gradually increased (Figure 2A) while the expression of occludin (Figure $2 \mathrm{~B}$ ) decreased. The expression of ZO-1 also gradually decreased under hypoxia conditions, the differences being statistically significant, except for comparison between 24 and 48 h (Figure 2C).

\section{Influence of HIF-2 $\alpha$ on the expression of occludin and ZO-1}

In order to explore the role of HIF- $2 \alpha$ in TJ protein, HIF- $2 \alpha$-shRNA lentivirus was allowed to infect rGENCs, which showed lower HIF-2 $\alpha$ expression levels. Non-silencing shRNA lentivirus was produced to infect rGENCs as the negative control group. The results showed that hypoxia led to HIF- $2 \alpha$ increase in cells, except in cells transfected with HIF-2 $\alpha$-shRNA (Figure 3A). After infection with 

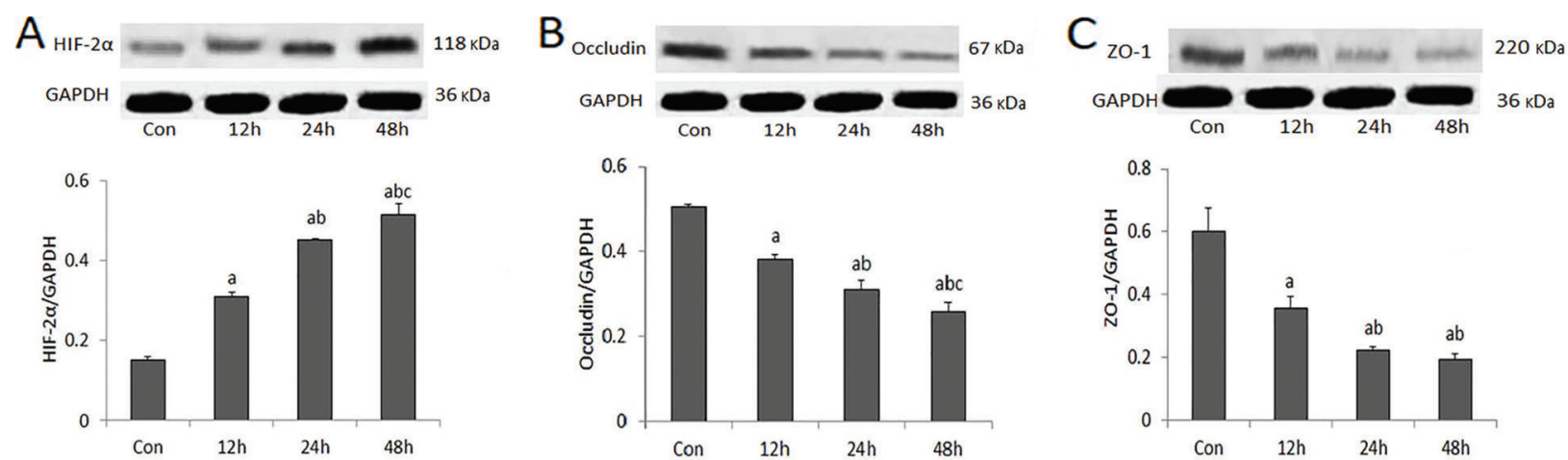

Figure 2. Influence of hypoxia on the expression of HIF-2 $\alpha$, occludin, and ZO-1. $A$, with the elongation of hypoxia time, the expression of HIF-2 $\alpha$ gradually increased and $B$, occludin gradually decreased. $C$, Expression of ZO-1 also gradually decreased under hypoxia conditions, the differences being statistically significant, except for comparison between 24 and $48 \mathrm{~h}$. Data are reported as means \pm SD. ${ }^{a} \mathrm{P}<0.01$ compared with control group; ${ }^{\mathrm{b}} \mathrm{P}<0.01$ compared with $12 \mathrm{~h}$; ${ }^{\mathrm{c}} \mathrm{P}<0.01$ compared with $24 \mathrm{~h}$ (ANOVA). Con: control group.
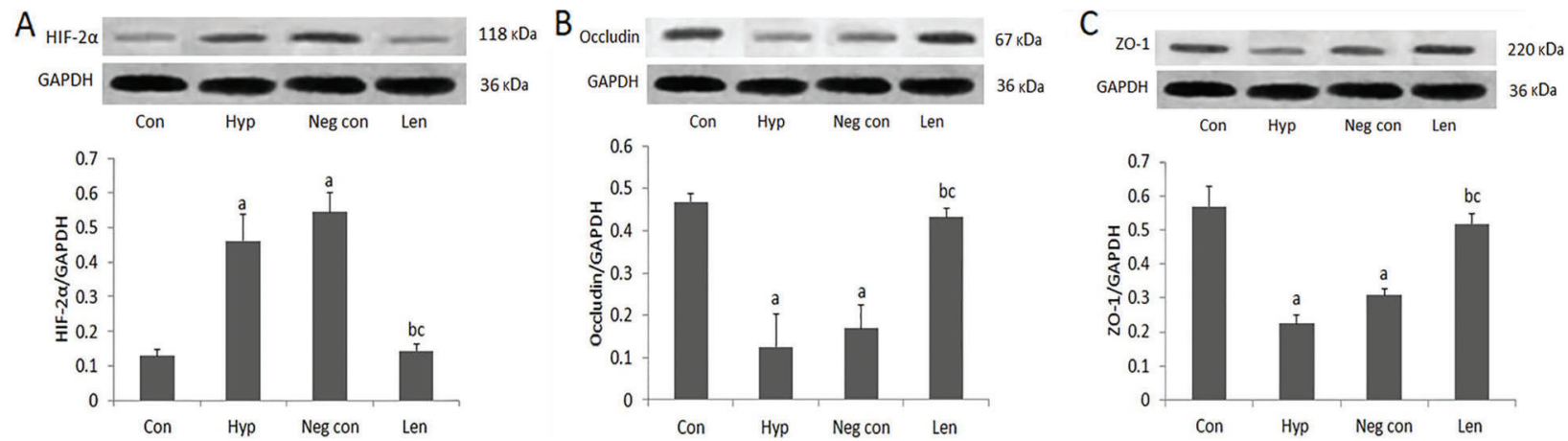

Figure 3. A, Hypoxia led to HIF-2 $\alpha$ increase in cells, except in cells transfected with HIF-2 $\alpha$-shRNA. $B$, After infection with HIF-2 $\alpha$ shRNA, the expression of occludin significantly increased in rat glomerular endothelial cells (rGENCs). $C$, The expression of ZO-1 under hypoxia conditions also increased. Data are reported as means \pm SD. Con: control group, rGENCs were cultured under $20.9 \% \mathrm{O}^{2}(n=3)$; Hyp: hypoxia group, rGENCs were cultured under $5 \% \mathrm{O}^{2}(n=3)$; Neg con: negative control group, rGENCs were infected with HIF-2 $\alpha$ lentivirus negative control vectors and cultured under hypoxic conditions $(n=3)$; Len: HIF- $2 \alpha$ lentivirus transfected group, rGENCs were transfected with HIF-2 $\alpha$ lentivirus and cultured under hypoxic conditions $(n=3)$. ${ }^{a} P<0.01$ compared with control group; ${ }^{b} P<0.01$ compared with hypoxia group; ${ }^{\mathrm{C}}<0.01$ compared with Neg con group (ANOVA).

Table 1. Expression of HIF-2 $\alpha$, occludin, and ZO-1 in different groups.

\begin{tabular}{lcccc}
\hline Group & Con & Hyp group & Neg con group & Len group \\
\hline HIF-2 $\alpha$ & $0.13 \pm 0.02$ & $0.46 \pm 0.08^{\mathrm{a}}$ & $0.54 \pm 0.06^{\mathrm{a}}$ & $0.14 \pm 0.02^{\mathrm{bc}}$ \\
Occludin & $0.47 \pm 0.04$ & $0.13 \pm 0.02^{\mathrm{a}}$ & $0.17 \pm 0.02^{\mathrm{a}}$ & $0.43 \pm 0.04^{\mathrm{bc}}$ \\
ZO-1 & $0.57 \pm 0.06$ & $0.22 \pm 0.03^{\mathrm{a}}$ & $0.31 \pm 0.02^{\mathrm{a}}$ & $0.52 \pm 0.03^{\mathrm{bc}}$ \\
\hline
\end{tabular}

Data are reported as means $\pm S D$. Con: control group; Hyp: hypoxia group; Neg con: Negative control group; Len: HIF-2 $\alpha$ lentivirus transfected group. ${ }^{\mathrm{a}} \mathrm{P}<0.01$ compared with control group; ${ }^{\mathrm{b}} \mathrm{P}<0.01 \mathrm{com}-$ pared with hypoxia group; ${ }^{\mathrm{C}} \mathrm{P}<0.01$ compared with Neg con group (ANOVA).

HIF-2 $\alpha$-shRNA, the expression of occludin increased significantly in rGENCs under hypoxia conditions, compared to the hypoxia and negative control groups (Figure 3B, $P<0.01)$. The data are reported in Table 1. The expression of ZO-1 under hypoxia conditions also increased in rGENCs after infection with HIF-2 $\alpha$-shRNA, compared to the hypoxia and negative control groups (Figure $3 \mathrm{C}$, $\mathrm{P}<0.01)$ 


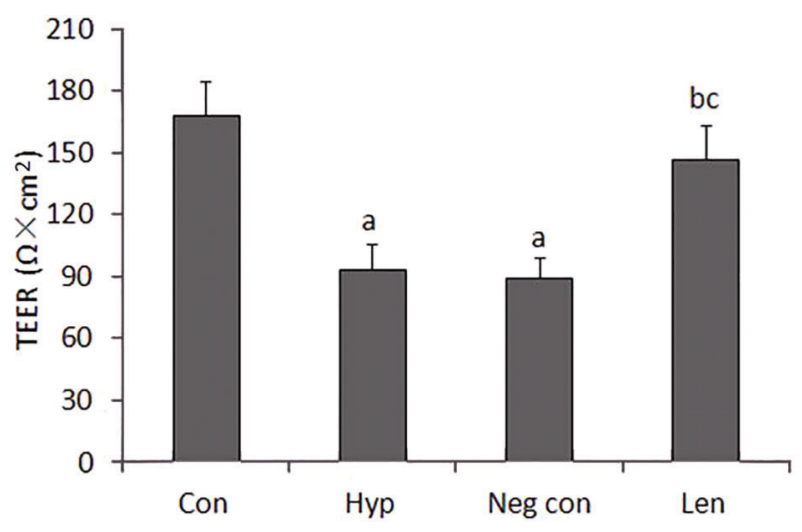

Figure 4. Influence of HIF-2 $\alpha$ on the permeability of rat glomerular endothelial cells. Data are reported as means \pm SD (ANOVA). Con: control group; Hyp: hypoxia group; Neg con: Negative control group; Len: HIF-2 $\alpha$ lentivirus transfected group. ${ }^{\mathrm{a}} \mathrm{P}<0.01$ compared with control group; ${ }^{b} \mathrm{P}<0.01$ compared with hypoxia group; ${ }^{\mathrm{C}} \mathrm{P}<0.01$ compared with Neg con group (ANOVA).

\section{Influence of HIF- $2 \alpha$ on the permeability of rGENCs}

After $24 \mathrm{~h}$ of exposure to hypoxia, rGENCs exhibited a significant decrease in TEER compared to the control group $(P<0.01)$. This indicated that the permeability of rGENCs was elevated after exposure to hypoxia. After infection with HIF- $2 \alpha$-shRNA, TEER became significantly higher compared to the hypoxia and negative control groups under hypoxia conditions $(P<0.01)$. The difference between the hypoxia and negative control groups was not significant $(P>0.05)$ (Figure 4).

\section{Discussion}

Hypoxia is one of the most common causes of vascular hyperpermeability (14-16). Following hypoxic exposure, the vascular permeability of the brain revealed a two-fold increase in fluorescence intensity, which is indicative of significant vascular leakage (17). Some studies have found that the integrity of the blood-brain barrier in rats is disrupted and permeability increased in hypoxic conditions, and the TJ proteins occludin and ZO-1 downregulation or derangement may be responsible for these changes $(18,19)$.

$\mathrm{TJ}$ is the most apical structure within the intercellular cleft, creating a paracellular barrier that is essential for survival of complex organisms. Integral TJ proteins are linked to each other as well as to the cytoskeleton by cytoplasmic adaptor proteins, such as ZO and occludin that provide the material foundation to restrict vascular permeability to molecules, allowing them to either diffuse across cell membranes or be carried across the membranes by specific membrane transporters (20-22). TJ proteins are dysregulated or can be genetically defective in numerous diseases, which may lead to three effects: i) impaired paracellular transport causing magnesium loss in the kidney, ii) increased paracellular transport of solutes and water causing leak-flux diarrhea, and iii) increased permeability to large molecules (23). A large body of evidence suggests that occludin and ZO-1 are the major components of endothelial TJ; changes in the localization, expression or phosphorylation of occludin/ZO-1 can lead to changes in TJ dysfunction and contribute to hyperpermeability. The rat brain endothelial cell line RBE4 exposure to hypoxia rapidly induced TJ disruption mainly through delocalization and increased tyrosine phosphorylation of occludin and ZO-1 with blood-brain barrier impairment (24). Chao et al. reported that high glucose $(30 \mathrm{mM})$ significantly increased paracellular permeability and attenuated expression of ZO-1 and occludin in HUVECs by enhancing amyloid precursor protein expression with increased amyloid beta-peptide production (25). This suggests that TJ proteins, such as occluding and ZO-1, play an important role in maintaining ideal vascular permeability and this regulation may be affected by hypoxia. In this study, we found that the expression of occludin and ZO-1 gradually decreased with the elongation of hypoxia time, meanwhile cell permeability was increased after 24-h exposure to hypoxia, both being significantly different compared to the control group.

This suggests that the hyperpermeability of cells under hypoxic conditions may be related to the reduction in occludin and ZO-1. A variety of occludin and ZO-1 expression patterns can occur under hypoxia conditions, such as the reduction of both in endothelial cells $(19,26,27)$, no expression changes in bone marrow (28) and brain endothelial cells after treatment for six hours by hypoxia (29), or a significant reduction in occludin expression, and no change in ZO-1 expression levels (30). It was speculated that experimental environment (in vivo or in vitro), culturing conditions, cell type, exposure time, and stimulus conditions are involved in this process. However, the protein occludin plays a crucial role in keeping the normal function of $\mathrm{TJ}$ and its downregulation is enough to cause the dysfunction of TJ $(31,32)$.

Hypoxia-inducible factors (HIFs) are ubiquitous master regulators of such hypoxic adaptation. HIF is a heterodimer composed of $\alpha$-subunit and $\beta$-subunit. HIF- $\alpha$ is regulated by oxygen-dependent proteolysis. Most cell types express HIF- $1 \alpha$, while HIF- $2 \alpha$ shows a more restricted pattern of expression. In the kidney, HIF- $1 \alpha$ is expressed in tubules, while HIF- $2 \alpha$ is confined to endothelial and interstitial cells (33). HIF-2 $\alpha$ was localized in glomeruli endothelial cells and podocytes in kidneys (9). Mice with HIF-2 $\alpha$ deficiency in endothelial cells developed normally, but displayed a variety of phenotypes, including increased vessel permeability and aberrant endothelial cell ultrastructure (12). Some studies indicated that endothelial HIF- $2 \alpha$ play a protective role against ischemia of the kidney. In a previous study, mice were more susceptible to renal ischemia-reperfusion injury such as elevated blood urea nitrogen when HIF-2 $\alpha$ expression was approximately 
one-half that of wild-type mice, whereas HIF- $1 \alpha$ expression was equivalent (28). Inactivation of endothelial HIF- $2 \alpha$, but not endothelial HIF- $1 \alpha$, resulted in increased expression of renal injury markers and inflammatory cell infiltration in the post-ischemic kidney (34). Those results indicated that HIF-2 $\alpha$ plays an important role in maintaining the normal permeability of blood vessels and protecting from ischemic renal damage. In our study, we found that the expression of HIF-2 $\alpha$ increased gradually with the elongation of hypoxia time while occludin and ZO-1 expression decreased with the hyperpermeability of cells. After knockdown of HIF-2 $\alpha$ expression, the content of occludin and ZO-1 was upregulated, and the permeability of cells

\section{References}

1. Pines A. High altitude acclimatization and proteinuria in East Africa. Br J Dis Chest 1978; 72: 196-198, doi: 10.1016/ 0007-0971(78)90041-4.

2. Chen W, Liu Q, Wang H, Chen W, Johnson RJ, Dong X, et al. Prevalence and risk factors of chronic kidney disease: a population study in the Tibetan population. Nephrol Dial Transplant 2011; 26: 1592-1599, doi: 10.1093/ndt/gfq608.

3. Jefferson JA, Escudero E, Hurtado ME, Kelly JP, Swenson $\mathrm{ER}$, Wener $\mathrm{M} \mathrm{H}$, et al. Hyperuricemia, hypertension, and proteinuria associated with high-altitude polycythemia. Am J Kidney Dis 2002; 39: 1135-1142, doi: 10.1053/ajkd.2002. 33380.

4. Blum MS, Toninelli E, Anderson JM, Balda MS, Zhou J, O'Donnell $\mathrm{L}$, et al. Cytoskeletal rearrangement mediates human microvascular endothelial tight junction modulation by cytokines. Am J Physiol 1997; 273: H286-H294.

5. Michel CC. Transport of macromolecules through microvascular walls. Cardiovasc Res 1996; 32: 644-653, doi: 10.1016/S0008-6363(96)00064-8.

6. Liang GH, Weber CR. Molecular aspects of tight junction barrier function. Curr Opin Pharmacol 2014; 19: 84-89, doi: 10.1016/j.coph.2014.07.017.

7. Balkovetz DF. Tight junction claudins and the kidney in sickness and in health. Biochim Biophys Acta 2009; 1788: 858-863, doi: 10.1016/j.bbamem.2008.07.004.

8. Edelblum KL, Turner JR. The tight junction in inflammatory disease: communication breakdown. Curr Opin Pharmacol 2009; 9: 715-720, doi: 10.1016/j.coph.2009.06.022.

9. Gunaratnam L, Bonventre JV. HIF in kidney disease and development. Journal of the American Society of Nephrology. J Am Soc Nephrol 2009; 20: 1877-1887, doi: 10.1681/ASN. 2008070804.

10. Ivan M, Kondo K, Yang $\mathrm{H}$, Kim W, Valiando J, Ohh M, et al. HIFalpha targeted for VHL-mediated destruction by proline hydroxylation: implications for O2 sensing. Science 2001; 292: 464-468, doi: 10.1126/science.1059817.

11. Jaakkola P, Mole DR, Tian YM, Wilson MI, Gielbert J, Gaskell SJ, et al. Targeting of HIF-alpha to the von HippelLindau ubiquitylation complex by O2-regulated prolyl hydroxylation. Science 2001; 292: 468-472, doi: 10.1126/science. 1059796.

12. Skuli N, Liu L, Runge A, Wang T, Yuan L, Patel S, et al. Endothelial deletion of hypoxia-inducible factor-2alpha decreased at the same time. Therefore, we hypothesized that HIF- $2 \alpha$ may have affected the permeability of endothelial cells through the regulation of occludin and ZO-1.

In conclusion, our results suggest that hypoxia could promote the increase of HIF- $2 \alpha$ content, which could induce increased permeability of rGENCs through reduction of the expression of occludin and ZO-1.

\section{Acknowledgment}

This study was supported by Natural Science Foundation of China (Grant No. 81460151).
(HIF-2alpha) alters vascular function and tumor angiogenesis. Blood 2009; 114: 469-477, doi: 10.1182/blood2008-12-193581.

13. Peng H, Wang C, Ye ZC, Chen YR, Zhang J, Chen ZJ, et al. How increased VEGF induces glomerular hyperpermeability: a potential signaling pathway of Rac1 activation. Acta Diabetol 2010; 47: 57-63, doi: 10.1007/s00592-009-0121-8.

14. Gavrilovskaya IN, Gorbunova EE, Mackow ER. Hypoxia induces permeability and giant cell responses of Andes virus-infected pulmonary endothelial cells by activating the mTOR-S6K signaling pathway. J Virol 2013; 87: 1299913008, doi: 10.1128/JVI.02103-13.

15. Zhu $\mathrm{H}$, Wang $\mathrm{Z}$, Xing $\mathrm{Y}, \mathrm{Gao} \mathrm{Y}, \mathrm{Ma} \mathrm{T}$, Lou L, et al. Baicalin reduces the permeability of the blood-brain barrier during hypoxia in vitro by increasing the expression of tight junction proteins in brain microvascular endothelial cells. $J$ Ethnopharmacol 2012; 141: 714-720, doi: 10.1016/j.jep.2011.08.063.

16. Liu T, Guevara OE, Warburton RR, Hill NS, Gaestel M, Kayyali US. Modulation of HSP27 alters hypoxia-induced endothelial permeability and related signaling pathways. J Cell Physiol 2009; 220: 600-610, doi: 10.1002/jcp.21773.

17. Fischer S, Wobben M, Marti HH, Renz D, Schaper W. Hypoxia-induced hyperpermeability in brain microvessel endothelial cells involves VEGF-mediated changes in the expression of zonula occludens-1. Microvasc Res 2002; 63: 70-80, doi: 10.1006/mvre.2001.2367.

18. Kaur C, Ling EA. Blood brain barrier in hypoxic-ischemic conditions. Curr Neurovasc Res 2008; 5: 71-81, doi: 10.2174/ 156720208783565645.

19. Hao L, Guo X, Zou C, Zhou H, Tian H, Zhang Y. Hyperbaric oxygen preconditioning ameliorates blood-brain barrier damage induced by hypoxia through modulation of tight junction proteins in an in vitro model. Croat Med J 2016; 57: 51-57, doi: 10.3325/cmj.2016.57.51.

20. González-Mariscal L, Tapia R, Chamorro D. Crosstalk of tight junction components with signaling pathways. Biochim Biophys Acta 2008; 1778: 729-756, doi: 10.1016/j.bbamem.2007.08.018.

21. Anderson JM, Van Itallie CM. Physiology and function of the tight junction. Cold Spring Harb Perspect Biol 2009; 1: a002584, doi: 10.1101/cshperspect.a002584.

22. Schneeberger EE, Lynch RD. The tight junction: a multifunctional complex. Am J Physiol Cell Physiol 2004; 286: C1213-C1228, doi: 10.1152/ajpcell.00558.2003. 
23. Krug SM, Schulzke JD, Fromm M. Tight junction, selective permeability, and related diseases. Semin Cell Dev Biol 2014; 36: 166-176, doi: 10.1016/j.semcdb. 2014.09.002.

24. Engelhardt S, Al-Ahmad AJ, Gassmann M, Ogunshola OO. Hypoxia selectively disrupts brain microvascular endothelial tight junction complexes through a hypoxia-inducible factor1 (HIF-1) dependent mechanism. J Cell Physiol 2014; 229 : 1096-1105, doi: 10.1002/jcp.24544.

25. Chao AC, Lee TC, Juo SH, Yang DI. Hyperglycemia Increases the Production of Amyloid Beta-Peptide Leading to Decreased Endothelial Tight Junction. CNS Neurosci Ther 2016; 22: 291-297, doi: 10.1111/cns.12503.

26. Won S, Sayeed I, Peterson BL, Wali B, Kahn JS, Stein DG. Vitamin D prevents hypoxia/reoxygenation-induced bloodbrain barrier disruption via vitamin $\mathrm{D}$ receptor-mediated NF-kB signaling pathways. PLoS One 2015; 10: e0122821, doi: 10.1371/journal.pone.0122821.

27. Ma X, Zhang H, Pan Q, Zhao Y, Chen J, Zhao B Hypoxia/ aglycemia-induced endothelial barrier dysfunction and tight junction protein downregulation can be ameliorated by citicoline. PLoS One 2013; 8: e82604, doi: 10.1371/journal. pone.0082604.

28. Brown RC, Mark KS, Egleton RD, Huber JD, Burroughs AR, Davis TP. Protection against hypoxia-induced increase in blood-brain barrier permeability: role of tight junction proteins and NFkappaB. J Cell Sci 2003; 116: 693-700, doi: 10.1242/ jcs.00264.

29. Brown RC, Davis TP. Hypoxia/aglycemia alters expression of occludin and actin in brain endothelial cells. Biochem Biophys Res Commun 2005; 327: 1114-1123, doi: 10.1016/ j.bbrc.2004.12.123.

30. Bauer AT, Burgers HF, Rabie T, Marti HH. Matrix metalloproteinase- 9 mediates hypoxia-induced vascular leakage in the brain via tight junction rearrangement. Journal of cerebral blood flow and metabolism. J Cereb Blood Flow Metab 2010; 30: 837-848, doi: 10.1038/jcbfm.2009.248.

31. Persidsky Y, Ramirez S H, Haorah J, Kanmogne GD. Bloodbrain barrier: structural components and function under physiologic and pathologic conditions. J Neuroimmune Pharmacol 2006; 1: 223-236, doi: 10.1007/s11481-006-9025-3.

32. Tavelin S, Hashimoto K, Malkinson J, Lazorova L, Toth I, Artursson P. A new principle for tight junction modulation based on occludin peptides. Mol Pharmacol 2003; 64: 1530-1540, doi: 10.1124/mol.64.6.1530.

33. Nangaku M, Inagi R, Miyata T, Fujita T. Hypoxia and hypoxia-inducible factor in renal disease. Nephron Exp Nephrol 2008; 110: e1-7, doi: 10.1159/000148256.

34. Kapitsinou PP, Sano H, Michael M, Kobayashi H, Davidoff $\mathrm{O}$, Bian A, et al. Endothelial HIF-2 mediates protection and recovery from ischemic kidney injury. J Clin Invest 2014; 124: 2396-2409, doi: 10.1172/JCl69073. 